\title{
Comparison of Acetylation and Alkali Treatments on the Physical and Morphological Properties of Raffia Palm Fibre Reinforced Composite
}

\author{
Anike David Chukwudi", Onuegbu Theresa Uzoma, Ugochukwu-Aniefuna Anthonia Azuka, \\ Ezuh Cyprian Sunday
}

Department of Pure and Industrial Chemistry, Nnamdi Azikiwe University Awka, Anambra State, Nigeria

Email address:

cardinaldavid24@gmail.com (D.C. Anike)

\section{To cite this article:}

Anike David Chukwudi, Onuegbu Theresa Uzoma, Ugochukwu-Aniefuna Anthonia Azuka, Ezuh Cyprian Sunday. Comparison of Acetylation and Alkali Treatments on the Physical and Morphological Properties of Raffia Palm Fibre Reinforced Composite. Science Journal of Chemistry. Vol. 3, No. 4, 2015, pp. 72-77. doi: 10.11648/j.sjc.20150304.12

\begin{abstract}
This work studied the comparison of the effects of acetylation and alkali treatments on the physical and morphological properties of raffia palm fibre polyester composites. The clean raffia palm fibres obtained from raffia palm tree were pre-treated using acetylation and alkali (mercerization) methods. The treated fibres were dried, ground and incorporate into polyester resin at various fibre loads of $0 \%, 5 \%, 10 \%, 15 \%$ and $20 \%$. The treated fibre composite samples were subjected to tensile tests according to ASTM D638 using Instron model 3369. The microhardness test was done using microhardness tester (LECO/M700AT). The scanning electron micrographs of the samples were taken using Scanning electron microscope (SEM) machine, model EVO/MA 10. The results of the analyses showed that the composites of the acetylated fibre improved the properties of the composites for ultimate tensile strength, better than the composites of alkali(mercerized) treated fibre, while the latter gave better modulus of elasticity and extension at break. Both the treatment methods showed increase in microhardness for the composites as fibre loads increases, but the acetylated fibre composites gave better results at each of the fibre loads of $5 \%, 10 \%, 15 \%$ and $20 \%$, studied. The SEM of the acetylated fibre composites, especially the $5 \%$ fibre load, showed better fibre-matrix interfacial bonding than the alkali treated fibre composites.
\end{abstract}

Keywords: Raffia Palm Fibre, Polyester Resin, Composite, Acetylation, Alkali (Mercerization) Treatments

\section{Introduction}

There is an increasing interest in the use of natural fibres as reinforcing components in fibre reinforced polymeric materials due to their enormous properties such as low density, low cost, renewability, biodegradability and environmentally friendliness [1]. The natural fibres have the potential to be used as a replacement for glass or other conventional reinforcement materials in composites. The combination of interesting mechanical and physical properties, together with their environmental friendly character has motivated a number of industrial sectors to consider these fibres as potential materials to replace synthetic fibres in environmentally safe products [1]. An interesting environmental friendly alternative for the use of synthetic fibres as reinforcement in engineering composites are lignocellulosic natural fibres such as flax, jute, etc.
Recent reports indicate that cellulose based natural fibres can very well be used as reinforcement in polymer composites, replacing more expensive and non-renewable synthetic fibres such as glass fibre, due to the potential for recycling of the material form [2]. Natural fibres come from renewable source that in principle is exhaustible; they are biodegradable [3]

However, there are some bottlenecks associated with natural fibres, which have to be tackled before they can be employed in polymer composites [4]. Natural fibres are hydrophilic as they are derived from lignocelluloses, which contain strongly polarized hydroxyl groups. The major limitations of using these fibres as reinforcements in such matrices include poor interfacial adhesion between polar hydrophilic fibres and non polar-hydrophilic matrix. Cellulose is a semicrystalline polysaccharide with a large amount of hydroxyl group in cellulose, giving hydrophilic nature to natural fibre when used to reinforce hydrophobic 
matrices; the result is a very poor interface and poor resistance to moisture absorption [5].

Chemical pretreatment of the natural fibre can help to overcome such limitations to enhance the compatibility between fibre and the matrices, resulting in improved performance of fibre-reinforced composites [6]. Different surface treatment methods such as mercerization (alkali treatment), isocyanate treatment, acrylation, benzoylation, latex coating, permanganate treatment, acetylation, silane treatment and peroxide treatment have been applied on the fibre to improve its strength, size and its shape and the fibre-matrix adhesion [6, 7].

Alkali treatment of natural fibres is known to improve the stiffness, strength, and dynamic flexural moduli of the composites, indicating an increased interfacial bond strength and adhesion between the matrix and the fibres [7]. Alkaline processing directly influences the cellulosic fibril, the degree of polymerization and the extraction of lignin and hemicellulosic compounds [8].

To introduce plasticization to cellulosic fibres, acetylation of natural fibres is a well-known esterification method [4, 9]. Fibers are acetylated with and without an acid catalyst to graft acetyl groups onto the cellulose structure. The agent reacts with the hydrophilic hydroxyl groups and swells the fiber cell wall. The fiber cell wall is thereby stabilized against moisture, improving dimensional stability and environmental degradation [10]. Acetylation is beneficial in reducing the moisture absorption on natural fibres. The reinforcement of polyester with various cellulosic fibers has been widely reported [11].

The aim of this work is to compare the effects of acetylation and alkali treatments on the physical and morphological properties of raffia palm fibre polyester composites.

\section{Materials and Methods}

\subsection{Material}

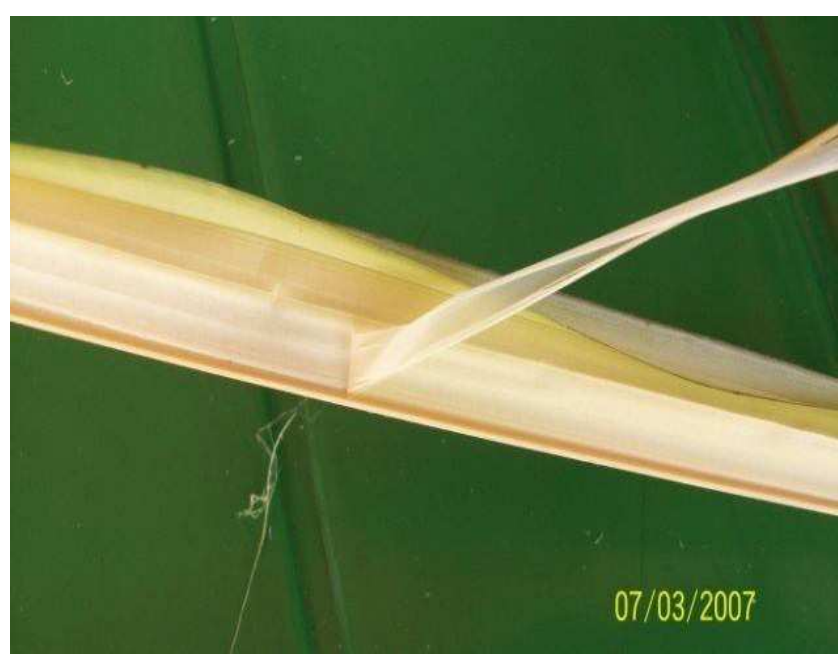

Plate 1. Extracting of the raffia fibre.

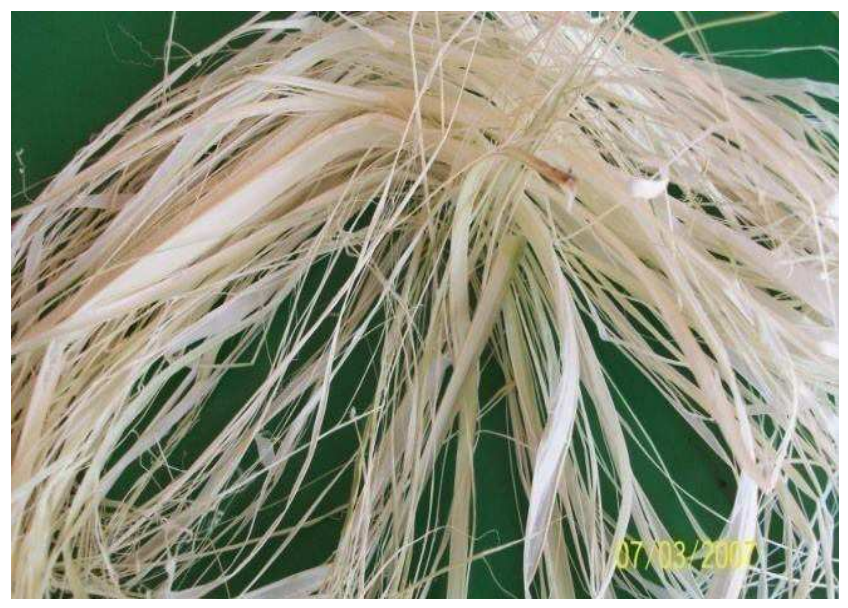

Plate 2. Raffia palm fibres.

The raffia palm fibres were sourced from raffia palm trees near a stream at Nchatancha, Enugu state and the chemicals (ortho unsaturated-polyester resin, methyl ketone peroxide and cobalt octoate) were bought from Polyconsult venture (25 ogunleti street), Ojota Lagos.

\subsection{Method}

\subsubsection{Preparation of Materials}

The raffia fibres were taken off from the pinnate leaves. Thereafter, the fibres were washed thoroughly and allowed to dry under the sun. Plate 1-2.

\subsubsection{Chemical Pretreatment of the Fibres}

The raffia palm fibres were divided into two (2) portions. A portion was treated using alkali treatment method (mercerization) while the other portion was treated using acetylation method. The alkali and acetylation treatment methods were carried out following the method reported by Aziz et al. [8].

a) Alkali Treatment (Mercerization)

$10 \%$ sodium hydroxide $(\mathrm{NaOH})$ solution was used to soak the clean fibres at temperature of $30^{\circ} \mathrm{C}$ for an hour. Fibres were then removed from the $\mathrm{NaOH}$ solution and washed thoroughly in plentiful of distilled water to remove excess $\mathrm{NaOH}$ (or nonreacted alkali).

b) Acetylation Treatment

Clean raffia palm fibres were first soaked in $5 \% \mathrm{NaOH}$ solution for one hour at $30^{\circ} \mathrm{C}$. Then, the fibres were decanted and soaked in glacial acetic acid for another one hour at $30^{\circ} \mathrm{C}$. Thereafter, the fibres were decanted and finally soaked in acetic anhydride containing few drops of concentrated $\mathrm{H} 2 \mathrm{SO} 4$ for 5 minutes at the same temperature. The fibres were drained and sun dried.

Later on, the fibres (alkali treated and acetylated treated) were taken to electric oven, where they were oven-dried at temperature of $70^{\circ} \mathrm{C}$ for 2 hours. The oven-dried fibres were ground into small particle sizes, not up to $1 \mathrm{~mm}$.

c) Preparation of the Composite

The moulds used were thoroughly coated with Polyvinyl Alcohol (PVA), and allowed to dry. A thin film formed on the mould when the PVA dried, acted as the mould releasing 
agent. The unsaturated polyester resin was then mixed with different loads $(5 \%, 10 \%, 15 \%$, and $20 \%)$ of the raffia palm fibres, following the steps given below.

First, the unsaturated polyester resin was weighed in a glass beaker, using a digital electronic balance. 2\% (by weight of the unsaturated polyester resin) of the catalyst, methyl ethyl ketone peroxide (MEKP), was added and the mixture stirred for 2 minutes. After which, 1\% (by weight of the unsaturated polyester resin) of the accelerator, cobalt octoate, was added and stirred for additional 2 minutes. Thereafter, the ground treated-raffia palm fibres were then added gradually and stirred to allow for proper dispersion of the fibres within the gel-like mixture. Then, the prepared formulation was poured into the mould, and allowed to cure for one hour. After, the cured samples were carefully removed from the mould and trimmed very well. The formulation used is shown in table 1 below, for each of the treatment methods.

Table 1. Formulation of Raffia palm fibre-Polyester Composites.

\begin{tabular}{lllll}
\hline Materials & \multicolumn{4}{l}{ Weight in Grammes } \\
\hline Raffia palm fibre & $(5 \%)$ & $(10 \%)$ & $(15 \%)$ & $(20 \%)$ \\
& $5 \mathrm{~g}$ & $10 \mathrm{~g}$ & $15 \mathrm{~g}$ & $20 \mathrm{~g}$ \\
Ortho unsaturated polyester & 95.00 & 90.00 & 85.00 & 80.00 \\
MEKP as Catalyst (2\%) & 1.90 & 1.80 & $1.7 \mathrm{O}$ & 1.60 \\
Cobalt octoate as Accelerator & 0.95 & 0.90 & 0.85 & 0.80 \\
$(1 \%)$ & & & \\
\hline
\end{tabular}

\subsection{Characterization of the Samples}

Tensile Tests: Test for tensile properties were carried out as described in ASTM method D638, using Instron Universal testing machine (3369 model). Each tensile specimen was positioned in the Instron Universal tester and then subjected to tensile load. As the specimen stretches, the computer generates the graph as well as all the desired parameters. The various properties determined include; ultimate tensile strength, modulus of elasticity and extension at breaks

Microhardness test: The Microhardness test was done using microhardness tester, LECO/M700AT. The test was carried out by forcing a diamond cone indenter into the surface of the hard specimen, to create an impression. Microhardness testing is a method of measuring the hardness of a material to deformation, on a microscopic scale [12].

Scanning Electron Microscopy Test: The Microstructure of the modified fibre-polymer matrix interface was examined using a scanning electron microscope (SEM), EVO MA/10 Model. The samples were cut into small sizes, $1 \mathrm{~cm}$ by $1 \mathrm{~cm}$, and placed on the sample holder, inside the machine, using carbon tape. The scanning electron microscope produced images of the samples by scanning them with focused beam of electrons that detect information about the samples' interfacial bonding, between the fibre and polymer matrix to indicate the extent of fibre-matrix adhesion.

\section{Results and Discussion}

The test results of the physical properties of the composites samples are shown in Table 2, and Fig 1-4.

Table 2. Results of the Physical Properties of the Composites.

\begin{tabular}{lllll}
\hline Composite & $\begin{array}{l}\text { Ultimate } \\
\text { tensile } \\
\text { strength } \\
\left(\mathbf{N} / \mathbf{m m}^{2}\right)\end{array}$ & $\begin{array}{l}\text { Modulus } \\
\text { of } \\
\text { Elasticity } \\
\left(\mathbf{N} / \mathbf{m m}^{2}\right)\end{array}$ & $\begin{array}{l}\text { Extension } \\
\text { at break } \\
(\mathbf{m m})\end{array}$ & Microhardness \\
\hline $\mathrm{C}_{0}$ & 23.05 & 782.16 & 3.77 & 12.10 \\
$\mathrm{ALK}_{5}$ & 11.27 & 986.98 & 3.08 & 13.50 \\
$\mathrm{ALK}_{10}$ & 22.45 & 1360.46 & 3.25 & 14.10 \\
$\mathrm{ALK}_{15}$ & 18.43 & 846.91 & 3.40 & 14.20 \\
$\mathrm{ALK}_{20}$ & 13.86 & 924.20 & 3.47 & 14.40 \\
$\mathrm{ACT}_{5}$ & 20.07 & 793.50 & 2.96 & 14.00 \\
$\mathrm{ACT}_{10}$ & 27.78 & 832.74 & 2.60 & 14.80 \\
$\mathrm{ACT}_{15}$ & 15.41 & 855.95 & 2.43 & 14.90 \\
$\mathrm{ACT}_{20}$ & 23.50 & 900.93 & 3.08 & 15.90 \\
\hline
\end{tabular}

$\mathrm{C}_{\mathrm{o}}=$ control sample, i.e. $0 \%$ fibre or $100 \%$ polyester. $\mathrm{ALK}_{5}, \mathrm{ALK}_{10}, \mathrm{ALK}_{15}$, $\mathrm{ALK}_{20}$ are composite samples containing 5\%,10\%, 15\% and $20 \%$ alkali treated raffia palm fibres respectively. $\mathrm{ACT}_{5}, \mathrm{ACT}_{10}, \mathrm{ACT}_{15}$ and $\mathrm{ACT}_{20}$ are composite samples containing $5 \%, 10 \%, 15 \%$ and $20 \%$ acetylated raffia palm fibres respectively.

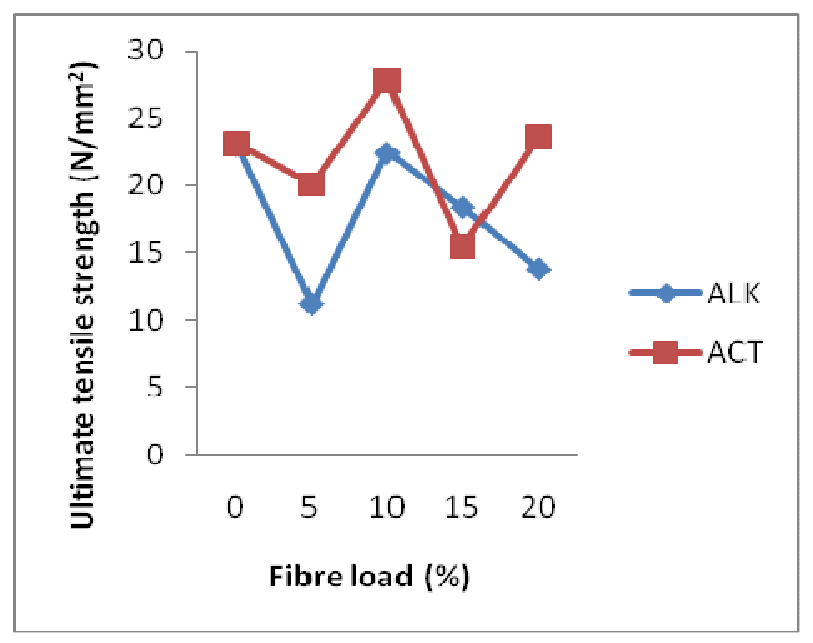

Fig. 1. Effect of Fibre Loads on tensile strength.

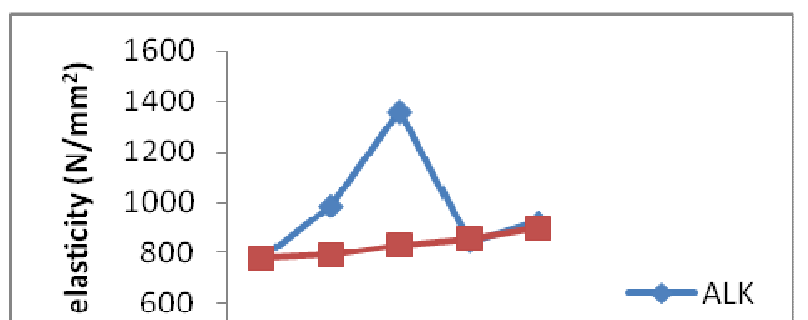


(mercerized) and acetylated fibres. The results of the acetylated treated fibre composites showed higher values at $5 \%, 10 \%$ and $20 \%$, than the mercerized fibre composites, but $15 \%$ fibre load of the mercerized is higher than same percent of acetylated, by $3.02 \mathrm{~N} / \mathrm{mm}^{2}$. Thus, acetylation can be seen to have a substantial increase in the ultimate tensile strength of the composites.

Fig. 2 shows the results of the modulus of elasticity, a measure of the stiffness and resistant to stress. From the results, the modulus of elasticity of the alkali treated (mercerized) composites gave higher values at the 5\%,10\% and $20 \%$, than the acetylated treated fibre composites, but $15 \%$ fibre load of the acetylated is higher than the same percent mercerized fibre composites by $9.04 \mathrm{~N} / \mathrm{mm}^{2}$.

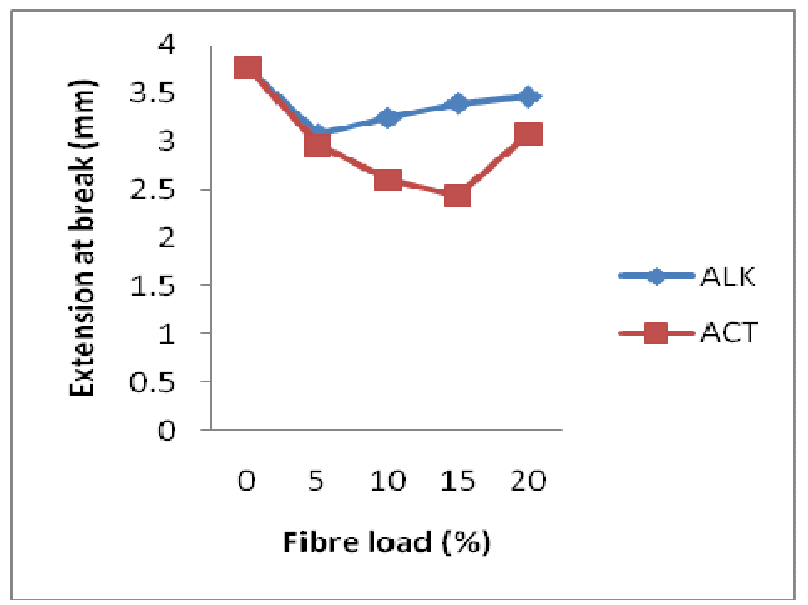

Fig. 3. Effect of Fibre Loads on Extension at Break.

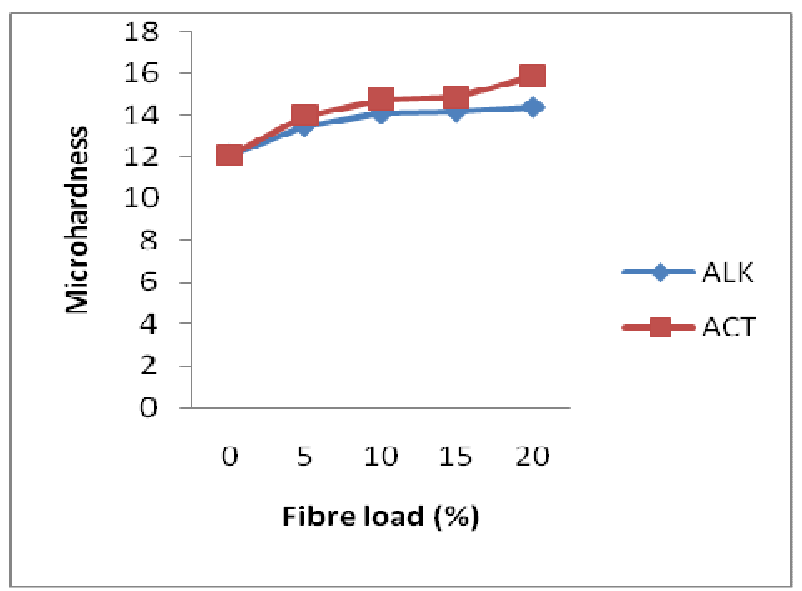

Fig. 4. Effect of Fibre loads on the Microhardness.

From fig.3, the graph shows that the extension at break for each of fibre loads of $5 \%, 10 \%, 15 \%$ and $20 \%$ mercerized fibre composites are better than the corresponding fibre loads of acetylated fibre composites. Although, the control sample ( $100 \%$ polyester) gave highest value of $3.77 \mathrm{~mm}$, than all the treated composites.

From fig. 4, it can be seen that both treatments as well as the increase in the fibre loads increase the microhardness of the composites. The microhardness for each of fibre loads of $5 \%, 10 \%, 15 \%$ and $20 \%$ of the acetylated treated fibre composites increased more than the corresponding alkali treated composites.

Plates 3-6 and 7-10; show the scanning electron microscopy of acetylated treated fibre composites and alkali treated fibre composites, respectively. The results showed that the micrographs of the acetylated fibre composites, especially the $5 \%$, showed better fibre-matrix interfacial bonding than the alkali treated fibre composites.

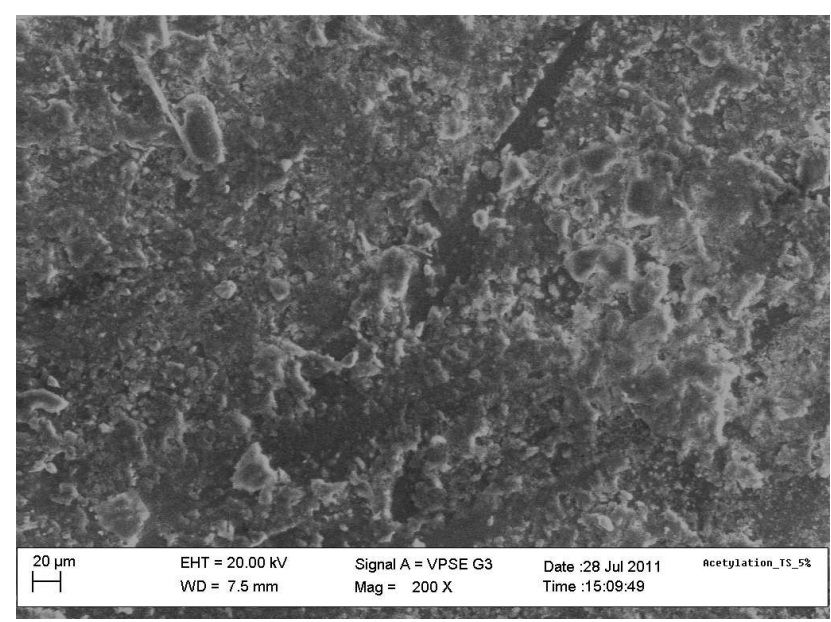

Plate 3. SEM of 5\% acetylated fibre composite.

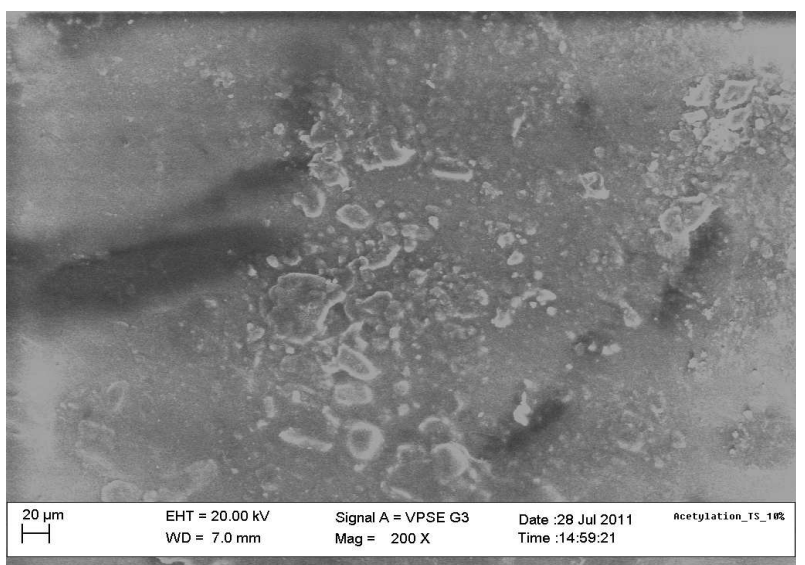

Plate 4. SEM of $10 \%$ acetylated fibre composite.

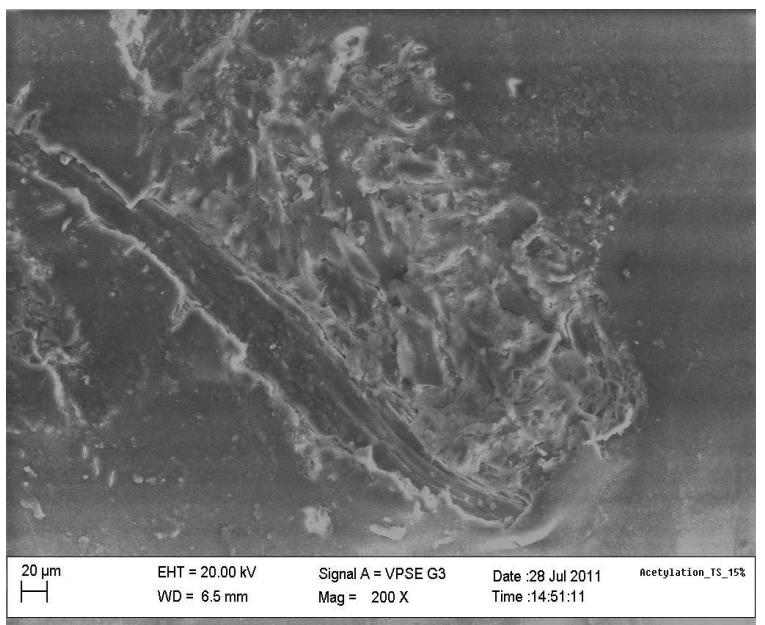

Plate 5. SEM of $15 \%$ acetylated fibre composite. 


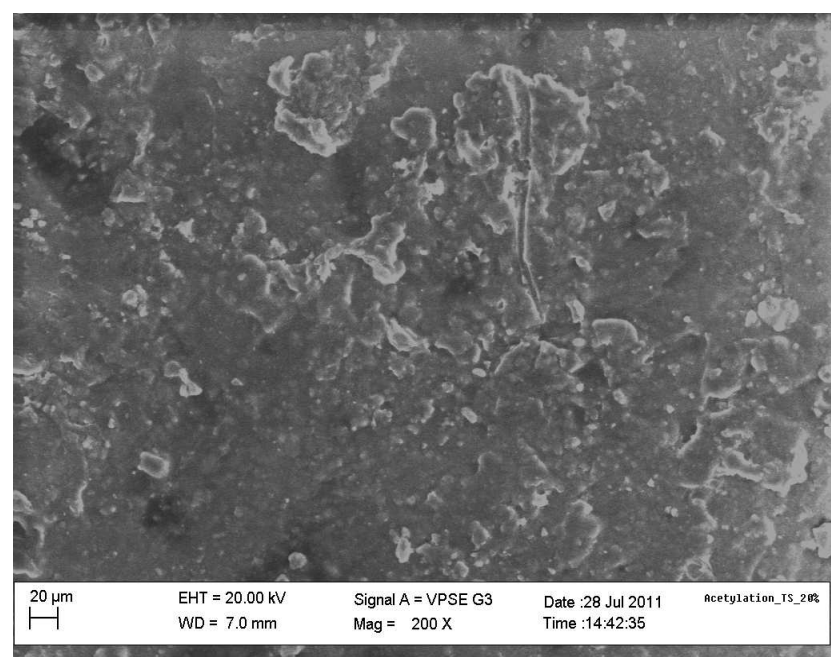

Plate 6. SEM of $20 \%$ acetylated fibre composite.

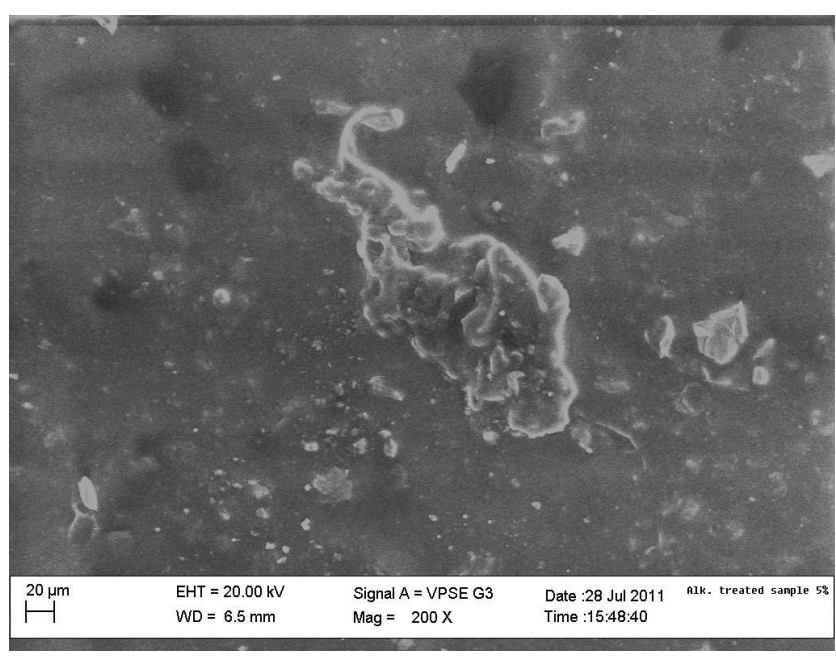

Plate 7. SEM of $5 \%$ alkali fibre composite.

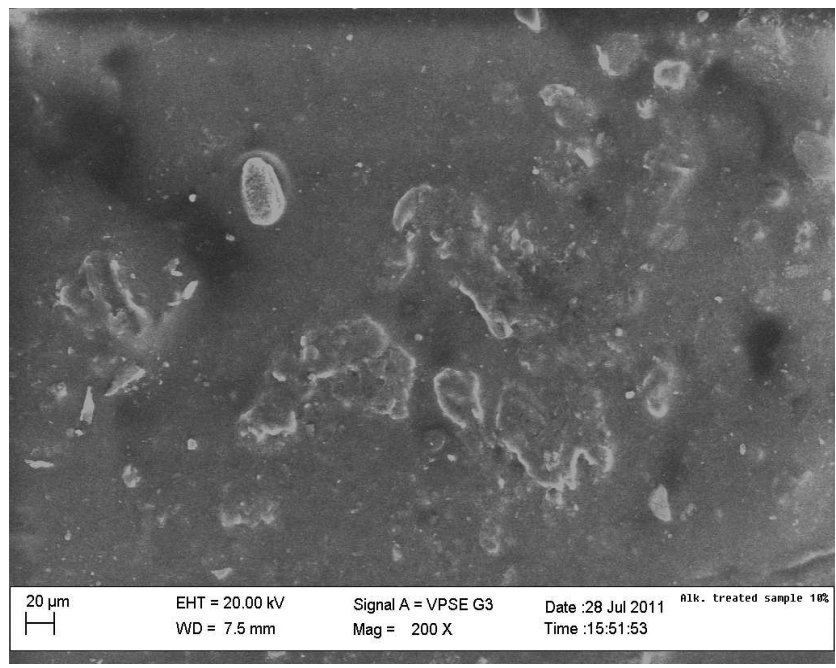

Plate 8. SEM of $10 \%$ alkali fibre composite.

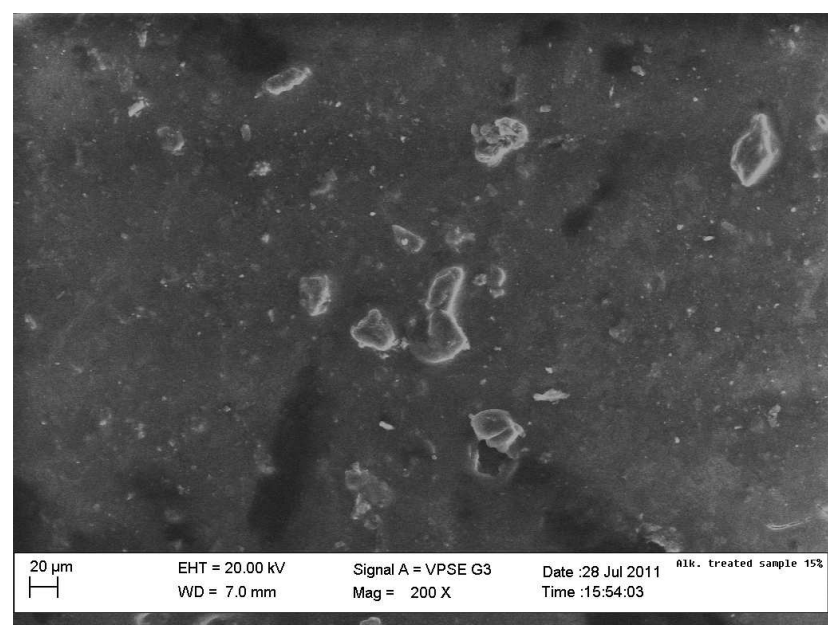

Plate 9. SEM of $15 \%$ alkali fibre composite.

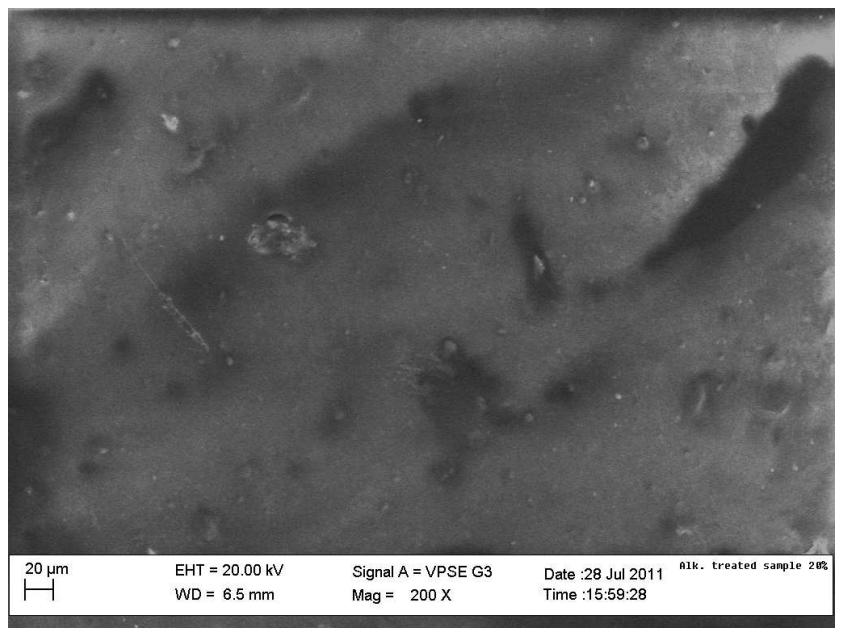

Plate 10. SEM of $20 \%$ alkali fibre composite.

\section{Conclusion}

From the results obtained, it can be established that the composites of the mercerized fibre improved the modulus of elasticity and extension at break better than the acetylated treated composites, while that of the acetylated showed better ultimate tensile strength and the microhardness better than mercerized ones. For the scanning electron micrographs, the acetylated fibre composites (best at 5\%) gave clearer fibre-matrix interfacial bonding.

\section{Recommendations}

We recommend that raffia palm fibres should be used as an alternative for synthetic fibre in polymer reinforcement, as the fibres are cheap, available and biodegradable. Also, that other forms of fibre pretreatment methods, short particle sizes instead of ground ones and more fibre loads to polymer matrix may still be implored. 


\section{Acknowledgements}

The authors wish to thank the staff of Engineering Material Development Institute, Akure where the samples were prepared and characterized and SHESTCO Sheda, Abuja, where the SEM was carried out.

\section{References}

[1] A.S. Singha, and V.K. Thankur (2008): Saccharum Cilliare Fiber Reinforced Polymer Composite. Journal of Chemistry, 5(4):78.

[2] B. Wang, S. Panigralic, W. Crarar and L. Tabil (2003): Application of Pretreated Flax Fibres in Composites. Canadian Society of Agricultural Engineering Sas Katton. Canada. 56-63.

[3] P.Wambua, J. Iven and I. Verpoest (2003): Natural Fibres: Can they replace glass in fibre reinforced plastics? Composite Science and Technology. 63: 1259-1264.

[4] E.S. Zainudin, S.M. Sapuan and T.M. Mohamad (2009): Mechanical Properties of Compression moulded Banana Pseudostem filled, unplasticized Polyvinyl Chloride Composite Polymer Plastic Technology and Engineering.48:97-101.

[5] Alvarez V. A., Ruscekaite R. A., Vazquez A. J.: Mechanical properties and water absorption behaviour of composites made from a biodegradable matrix and alkaline treated sisal fibres. Journal of Composite Materials, 37, 1575-1588 (2003).
[6] D. R. Anandjiwala and M. J. John (2007), Recent developments in chemical modification and characterization of natural fibre reinforced composites, Wiley InterScience, Society of Plastics Engineers, 188-207.

[7] S. H. Aziz, and M. P. Ansell (2004), The Effect of Alkalization and Fibre alingnment on the Mechanical and Thermal Properties of Kenaf and Hemp bast fibre Composites: Part I- Polyester resin matrix," composites: Science and technology 64(9), 1219-1230.

[8] A. Jahn, MW. Schroder, M. Fu“ ting, K. Schenzel, W. Diepenbrock (2002), Spectrochim Acta A: Mol Biomol Spectrosc 58:2271.

[9] I. O. Oladele, J.A. Omotoyinbo, J. O. T. Adewara (2010), Investigating the effect of chemical treatment on the constituents and tensile properties of sisal fibers', Journal of minerals \& materials characterization \& engineering, Vol. 9, No. 6, 569-582.

[10] A. K. Bledzki, A. A. Mamun, M. Lucka-Gabor, V. S. Gutowski (2008), The effects of acetylation on properties of flax fiber and its polypropylene composites, eXPRESS Polymer letters, Vol. 2, No. 6, 413-422.

[11] M.Depeepya, T.D.Raju, \& T.Jayananda (2012), Effect of alkali treatment on Mechanical and Thermal Properties of typha Angustifolia Fibre Reinforced Composites. Int. J. Mech. Ind. Eng (IJMIE), 1(4):12-14.

[12] F.W. Billmeyer. (2005), Textbook on Polymer Science $-3^{\text {rd }}$ ed. John Wiley and Sons, Singapore. 413 - 414. 